ALÉTHEIA

2014, 2(1) 57-67

Recibido: 30-04-2014

Aceptado: 25-08-2014

Palabras clave: vida ética. universidad. catedrático. interioridad.

Keywords: ethical life, university, professor, interiority.

Jorge Capella Riera

Profesor Emérito PUCP jcapell@pucp.edu.pe
La ética en la vida universitaria

\section{Ethics in university life}

\section{Jorge Capella Riera}

RESUMEN. Desde la perspectiva de la educación Superior, ante la crisis ética los educadores no hemos sido capaces de desarrollar un fundamento ético, ni una filosofía pública que tome en serio la relación que debe existir entre la universidad y una vida pública democrática. Sin embargo la crisis de la ética es una oportunidad para buscar clarificar, enriquecer y profundizar una respuesta. En este ensayo se aborda el vivir universitario, el papel del catedrático y la vida ética en la universidad. La ética tiene que dejar de reflejar la atomización de conductas individuales para convertirse en la manera de pensar, sentir, decir y hacer de la organización universitaria como un todo. Es importante el liderazgo ético de la universidad en la sociedad y uno de los roles más importantes de las autoridades es ser maestros éticos, por lo tanto inclusive al formar especialistas del más alto nivel académico, se tiene que valorar lo humanístico en la más amplia acepción del término. Se requiere un paradigma universitario global en el que el aprendizajeenseñanza sea sacado de los estrechos marcos de las relaciones gestadas en la interacción didáctica para entrar en las transformaciones de los procesos de semiotización de la vida cotidiana.

ABSTRACT. From the perspective of Higher education, with regard to ethical crisis, the educators have not been able to develop an ethical foundation or a public philosophy that takes seriously the relationship that should exists between the university and a democratic public life. However, the crisis of ethics is an opportunity to seek to clarify, enrich and deepen a response. In this essay, university living, role of professor and ethical life in the university are analyzed. Ethics has to stop reflectingthe atomization of individual behavior to become the way of thinking, feeling, saying and making the university organization as a whole. Ethical leadership of the university is important in the society and one of the most important roles of the authorities is to be ethical teachers, therefore even to train specialists of the highest academic level, humanistic has to be valued in the broadest sense of the term. A global university paradigm in which learning-teaching are taken out of the narrow frameworks of relations conceived in the educational interaction is required to enter in the transformation processes of everyday life's semiotization required. 
58 UNIFÉ - EPG

\section{Introducción}

$\mathbf{E}$ 1 mundo en que nos ha tocado vivir está en crisis, una crisis cuyas causas hay que verlas en la expansión del neoliberalismo y sus criterios economicistas, la globalización informativa y los cambios producidos por la ciencia y la técnica, entre otros elementos. Es así cómo se conforma el marco desde el cual se filtran y refractan las distintas opciones y posiciones ético/morales al interior de nuestras sociedades y a nivel mundial.

Ello nos ha inducido a un peligroso estilo de vida hedonista, consumista y derrochador como forma de expresar nuestro egoismo desde la ignorancia en la que nos movemos frecuentemente. (Díez Hochleitner, 1996)

Es más, como denunciaba Salvat (1994) “el orden moral aparece cuestionado y puesto como representativo de meras "ficciones" inútiles para la vida práctica. De una ética sin metafísica, habríamos pasado a una ética sin moral, toda vez que los postulados que la configuran (libertad, autonomía, voluntad, deber, racionalidad), se habrían mostrado como "entelequias" inventadas para poder darle sentido y fijación a un mundo que, en verdad, se mueve en eterno retorno y sin sentido."

$\mathrm{Y}$ desde una mirada netamente educativa debemos reconocer, con Giroux (1992) y Berlanga (1994), que, atrapada en la paradoja de exhibir indignación moral sin contar con una teoría bien definida de la ética y la moralidad, la teoría educativa -aun la más radical- ha sido incapaz de desplazarse desde la crítica hacia una visión sustantiva. En otras palabras, los educadores no hemos sido capaces de desarrollar un fundamento ético, ni una filosofía pública que tome en serio la relación que debe existir entre la universidad y una vida pública democrática.

No obstante lo dramático de lo que acabo de expresar, Simons (1998) considera "la crisis de la ética como una oportunidad para buscar clarificar, enriquecer y profundizar el sentido positivo y, sobre todo, imprescindible que tiene la dimensión ética de nuestra vida". Esto, sin duda, nos plantea un desafío que, como académicos, no podemos dejar de enfrentar.

Felizmente, es patente que la preocupación ética aparece hoy en los mejores representantes de muchos sectores del saber científico y del práctico: la biología, la medicina, la física, la economía, los negocios...

En la Declaración Mundial sobre la Educación Superior en el Siglo XXI: Visión y Acción (1998) ya se nos alertaba y alentaba al respecto: la Universidad tiene que hacer frente a imponentes desafíos por lo que "ha de emprender la transformación y la renovación más radicales que jamás haya tenido por delante, de forma que la sociedad contemporánea, que en la actualidad vive una profunda crisis de valores, pueda trascender las consideraciones meramente económicas y asumir dimensiones de moralidad y espiritualidad más arraigadas".

Ahora bien en una visión holística de lo universitario, el universo de requerimientos institucionales, -apunta De Longhi (2005)-, "'abarca dos direcciones: una hacia la formación integral, con capacidades disciplinares, pedagógico-didácticas, comunicacionales y de investigación, y la otra hacia el desarrollo de aptitudes y valores éticos para impulsar y llevar adelante propuestas innovadoras y soluciones a problemas relacionados con la realidad bio-sociocultural regional y nacional."

Como lo demanda el título del artículo y lo hasta ahora expuesto, en esta oportunidad voy a ocuparme del segundo de estos requerimientos tratando de establecer cómo la ética debe estar presente en la vida universitaria. Para ello acudo a algunos de los autores que han trabajado este tópico y de manera muy especial a Víctor Guédez y a Alberto Simons.

En cuanto al uso del género, en este escrito -contando con el perdón de las damas- empleo el masculino para facilitar la fluidez en el discurso.

Emplearé este esquema:

- Precisiones conceptuales.

- La ética en el vivir universitario.

- El catedrático y la vida ética en la universidad.

\section{Precisiones conceptuales}

La complejidad del asunto a tratar me exige 
que, antes de entrar al tema propiamente dicho, fije mi posición frente a los términos que tienen especial relevancia en este trabajo, sobre todo la ética.

\subsection{La ética}

Surge como el eje de las conductas individuales necesarias para que las instituciones, los países, las subregiones y el mundo asuman el compromiso de sobrevivir, de convivir y de vivir. La ética es parte de la espiritualidad por lo que podemos decir que es la ola que orienta la prospectiva del siglo XXI ya que, según Malraux (1999), “el siglo XXI será espiritual o no será".

Es más, mucho más: el hombre no puede elegir ser ético o no. En expresión de López Azpitarte (2011), que parafrasea a Sartre (1943), «el hombre está condenado a ser ético. El animal tiene su vida resuelta por el dinamismo de sus instintos a los que, por otra parte no puede escapar. Al hombre, en cambio, los instintos le son insuficientes y no se le ha dado un modo específico y determinado de ser y comportarse, sino que él mismo tiene que encontrarlo, y en ello se da conjuntamente el llamado ético y su dignidad de ser humano».

De esta suerte, la ética, apunta Guédez (2001), siempre demanda principios enraizados y conductas comprometidas que condicionan y fundamentan, que incentivan y orientan. "Es en el fondo de cada quien donde se encuentra el territorio propicio para el cultivo ético. Los seres humanos tenemos pendiente el desafío de meternos dentro de nuestra interioridad, a fin de reactivar la mismidad y reforzar la espiritualidad propicia para las mejores relaciones con Dios, con los demás, con la naturaleza y con nosotros mismos".

La ética, en esta posición, tiene que estar atenta a los antiguos valores que siguen siendo válidos y viables y a descubrir los valores que están emergiendo.

En este contexto, también se me impone precisar las distinciones entre ética y moral pues ambos términos suelen usarse como sinónimos. Me limitaré a insistir en lo dicho por Guédez, que "la ética procede de las convicciones y de las decisiones que no vienen desde fuera, sino desde dentro de nuestras conciencias.
En cambio la moral tiene que ver con las reglas y las órdenes, así como las tradiciones y costumbres que se nos imponen desde fuera. No cabe duda que la autoimposición interna y la represión externa encarnan dimensiones distintas pero necesarias dentro de la vida social y por ende organizacional".

Por último, en el ámbito universitario en que nos movemos, debo a lo menos mencionar a la deontología, es decir al conjunto de principios y reglas éticas que regulan y guían la actividad profesional. En ella, sostiene Regal (1988), se subraya el aspecto de compromiso incondicional que debe asumir el actor moral. Se usa sobre todo en el contexto de los colegios profesionales al considerar sus códigos de ética y sus tribunales de honor.

\subsection{La vida}

No hay forma de conocer lo que es la vida si no es viviendo, estando vivo, fluyendo, discurriendo con ella en el medio en que uno se desenvuelve, inserto en una determinada cultura.

El ser humano vive una vida verdaderamente humana, gracias a la cultura en un determinado ambiente social. En la variedad y riqueza de sus manifestaciones es ella la que hace al hombre un ser diferente y superior al mundo que lo rodea. Por eso el hombre no puede prescindir de la cultura por cuanto ésta abarca la totalidad de la vida de los seres humanos, de todos los elementos materiales y espirituales que se concatenan e interrelacionan mutuamente. Los materiales dan una respuesta a las necesidades de la humanidad y se relacionan con las funciones básicas, mientras que los espirituales pretenden satisfacer las necesidades y aspiraciones más íntimas, profundas de los seres humanos, tanto individual como colectivamente.

Lo dicho permite entender mucho mejor lo expresado por Castells (2001) cuando escribía: “quien quiera vivir bien tendrá que reunir dos condiciones: un alto nivel de educación y una gran adaptabilidad personal."

Para ser aún más preciso considero que desde la perspectiva de la psicología, la vida es un sentimiento 
60 UNIFÉ - EPG

apreciativo por las interacciones del yo con el medio, y, por reacción a dicho sentimiento, la lucha por sostener su homeostasis. Y en el ámbito religioso, la vida humana es un paso que conduce al alma, en un período de tiempo, de la inexistencia a la plenitud eterna.

\subsection{La universidad}

Sigo pensando que la idea que Mayor Zaragoza (1988) tenía de la universidad sigue vigente. Para él requerimos de una Universidad "inserta en la sociedad, conectada con las empresas e instituciones financieras que vean en ella la fuente de personal cualificado y la solución a problemas específicos de su área; una universidad independiente, pero relacionada con las instancias de poder al que asesora y proporciona información actualizada para la toma de decisiones; una universidad con capacidad creadora que ofrece fórmulas interdisciplinarias y estrategias imaginativas a la sociedad; una universidad especialmente rigurosa en la incorporación de su profesorado; con el único requisito de su capacidad y en número suficiente para la enseñanza especializada y para la investigación científica y técnica; una universidad con una amplia oferta curricular que pueda seguirse "a la medida" por los estudiantes de todas las edades; una enseñanza superior que posea los mecanismos de acceso de alumnado que permitan personalizar al máximo los criterios aplicables a la iniciación de estudios en los diversos centros y permanencia en los mismos; unos cursos intensivos de actualización y especialización permanentes; restando énfasis a la formalidad del título convencional para trasladar la mayor atención a la capacitación personal; una universidad que favorezca la movilidad de sus profesores y alumnos mediante los pertinentes acuerdos interinstitucionales y la cooperación en centros y organismos regionales e internacionales."

Sin embargo creo indispensable agregar que a todo lo dicho por Mayor hay que añadir: tomando en consideración criterios relacionados con las diferentes culturas, niveles sociales y consideraciones éticas ya que la universidad, como el país, es una continuidad: no es un hiato de la vida cultural. Es una continuidad que asegura la vida política y cultural del país en la que la ética debe tener un rol preponderante.

Es así como, tal como nos recuerda Cisneros (2009), "la universidad debe brindar la libertad a los miembros de la comunidad universitaria de opinar sobre los problemas éticos, culturales y sociales con total autonomía y plena responsabilidad. Así como propiciar que los miembros utilicen su capacidad intelectual y de prestigio moral para defender y difundir los valores universalmente aceptados, en especial la paz, la justicia, la libertad, la igualdad y la solidaridad".

\section{La ética en el vivir universitario}

La realidad en todas sus facetas es el lugar de estar de la universidad. Ese lugar es la sociedad a la cual pertenece. El saber, esencia de la universidad, no corresponde solamente a la esfera cognitiva del ser humano, puesto que éste es indivisible, corresponde también, aunque de modo diverso, a la esfera afectiva, al robustecimiento de la voluntad y al desarrollo de destrezas para la acción.

Guédez (2001) nos advierte que "mientras más independientes queremos ser del entorno, más dependemos de él." Siguiendo a este autor puedo afirmar que "no hay manera de escapar de los efectos que proceden del espacio y del tiempo histórico en donde nos insertamos. Esta realidad nos obliga a tomar conciencia de los problemas que ahí coexisten: la pobreza, la contaminación, la inseguridad, así como los desajustes asociados a la salud, la educación y la cultura. Esas exigencias involucran a las instituciones universitarias, pues ellas existen dentro de esos marcos y son susceptibles a las repercusiones de lo que ahí ocurra. En este juego de interacciones se define el perfil de la universidad, y muy particularmente su perfil ético pues el carácter ético de la universidad se construye de adentro hacia afuera y de afuera hacia adentro".

Veamos este asunto en dos niveles: personal e institucional.

\subsection{En el nivel personal}

El estudiante universitario es un joven adulto o un adulto joven, como diría Adam (1970), y -como 
dice él mismo- hay dos hechos incontrovertibles que justifican la educación del adulto: la inconclusión ontológica del ser humano y la confrontación dialéctica hombre-naturaleza, cuya síntesis, la cultura, es constantemente recreada mientras, a su vez recrea el entorno cultural y con ella la sociedad. Y el instrumento creador, de manera general, es la educación.

Es por esto que la educación universitaria debe estimular la formación integral de la persona humana, incluyendo la capacidad para la comunicación y el diálogo, el respeto a los demás, la sensibilidad frente a la belleza y el arte, el interés por la salud, el bienestar físico y el ambiente, así como el conjunto de actitudes y habilidades que formen el quehacer específico que cada quien haya elegido libremente como actividad central para su vida lo que le permitirá experimentar nuevas formas de comunicación, con una visión abierta, crítica y plural.

En efecto, la vida universitaria es una etapa que está llena de todo tipo de experiencias que se encargan de formar al estudiante no sólo como profesional, sino también como miembro para una mejor sociedad. Por ello el o la joven no debe permitir que esta nueva etapa se vea ocupada solamente por la presión de los estudios o por una auto-exigencia más de la necesaria. La mejor manera de vivirla es alcanzando un equilibrio.

$\mathrm{Y}$ este equilibrio se verá reforzado por las actividades artísticas, deportivas, culturales, de voluntariado o de innovación y emprendimiento, entre muchas otras. La vida universitaria implica también integrarse a la comunidad universitaria e insertarse en el entorno de la comunidad.

Es así como el estudiante puede asumir el impulso, la energía, la creatividad y la lealtad que procede de actuar con una conducta ética.

Hay muchas y diferentes formas de entender esta conducta. Me inclino por la manera en que Simons (1998) lo plantea. El ser humano:

- Como ser consciente, libre y por tanto responsable, se ve en la necesidad ineludible de elegir y de emitir juicios de valor para poder optar consciente, libre y responsablemente.

- Como ser en búsqueda de sentido percibe que no tiene un destino predeterminado de encontrar y dar un sentido a la vida (y a su propia vida) que oriente el quehacer de las personas y la sociedad. En esa búsqueda se ve comprometido por entero y no sólo con su inteligencia.

- Como ser histórico en búsqueda de autenticidad y humanidad se encuentra entre lo que es y lo que debe, puede y quiere ser; es decir pone en juego su autorrealización personal, social y trascendente y sólo alcanza su plenitud a través del llamado ético. Es el llamado a construir su propio ser en libertad.

- Como ser social y solidario es constitutivamente social, modela y es modelado por el medio socio - cultural. El bien y mal que hacemos repercute en los otros y viceversa. Si esto es así, la exigencia ética de construir la solidaridad es clara.

Lamentablemente muchos estudiantes solo pasan por la universidad, no hacen vida universitaria, como la que acabamos de considerar, por lo que durante el período de "formación", o en el mejor de los casos de estudios, no se da en ellos la posibilidad del proceso que se requiere para que se inicie un cierto cambio de vida.

Y sin embargo la UNESCO (1996), considera que incluso los dirigentes que trabajan a nivel nacional o regional necesitan un tipo de formación que les permita asumir sus responsabilidades profesionales como corresponde, sin separar de ellas su calidad de ciudadanos del mundo y de sus propios países. "Por lo tanto, en cualquier nivel de la educación universitaria, inclusive al formar especialistas del más alto nivel académico se tiene que valorar lo humanístico en la más amplia acepción del término, es decir, enseñar a la gente para que se comprenda a sí misma y a los otros y para comprender lo que ocurre a nivel mundial".

En síntesis el norte inteligente y efectivo de nuestro quehacer está en el planteamiento ético de los objetivos de la educación universitaria y en su encarnación. Se trata, dice Cardona (1990) de no perder de vista que su meta es la de formar hombres integros, personas; por tanto de restituir a la norma ética su primacía. 


\section{UNIFÉ - EPG}

\subsection{La ética en el nivel institucional.}

En este aspecto de la vida universitaria quiero precisar que, en el ámbito de la gestión, concibo la universidad como una organización que reconoce los aportes del mundo empresarial. $\mathrm{Y}$ en tal sentido, sigo a Guédez (2001) quien apunta que "una organización es una reorganización permanente o deja de ser una organización. Esta expresión, derivada de la tesis del «optimismo optimizable» de Morin (1994), sugiere la necesidad de disponer de un fuerte sistema de creencias, valores y conductas relacionadas, para asegurar que esos cambios se hagan en función de un eje cultural. Las organizaciones -en sus expresiones más tangiblesson la sumatoria de los significados de lo que piensan y de lo que dicen, así como de los resultados de lo que hacen. En definitiva, las organizaciones nacen a partir del germen de una cultura y se desarrollan en función de los enfoques de una cultura."

Esta realidad exige a la universidad un cambio. Parafraseando a Mejía (1996) me atrevo a decir que se requiere un paradigma universitario global en el que el aprendizaje-enseñanza sea sacado de los estrechos marcos de las relaciones gestadas en la interacción didáctica para entrar en las transformaciones de los procesos de semiotización de la vida cotidiana.

Ello supone un proyecto universitario institucional del que se desprenda un proyecto académico de formación profesional y de perfeccionamiento y de éste un proyecto currícular de cada carrera.

Estos proyectos son un compromiso de acción $\mathrm{o}$ un conjunto de actividades interrelacionadas, que se realizan para alcanzar un objetivo en un tiempo determinado. Cristalizan un conjunto de elementos que dan forma a la intención educativa de una comunidad universitaria.

Ahora bien, para Astudillo (1995), lo que da sentido y proyección a estos proyectos universitarios es el cumplimiento de su misión mediante el ejercicio de sus funciones de docencia, investigación, extensión y proyección social, asistencia técnica -o servicios a terceros- y gestión. Es por esto que el currículo debe recoger lo fundamental de los proyectos institucional y académico y tener muy en cuenta sus exigencias.

Concuerdo, una vez más, con Guédez (1985) quien sostiene que para cumplir con su misión la universidad, sea cual fuere el signo ideológico de quienes la regentan, debería plantearse fines académico-epistemológicos, fines socio-políticos y fines axiológicos tratando de mantener equilibrio entre ellos. Entre los fines axiológicos considera la formulación de una manera de sentir, de pensar y de hacer; es decir, de un estilo identificado con normas éticas.

No es mi intención ocuparme de cada uno de los elementos y dimensiones de los proyectos mencionados sino tan solo de ese estilo identificado con normas éticas a las que he aludido insistentemente.

Acabo de indicar que las organizaciones nacen a partir del germen de una cultura y se desarrollan en función de los enfoques de una cultura. Pues bien, es importante subrayar que la naturaleza de esta cultura debe ser más proactiva que reactiva. Esto parece obvio pero, sin embargo, debe reiterarse porque somos muy dados a plantear lo ético como un problema de corrupción más que de honestidad, con lo cual debilitamos el impacto de los mensajes. Más que hablar de los riesgos de la corrupción, hay que subrayar las bondades del comportamiento ético. La acepción proactiva de la ética encuentra un importante reforzamiento cuando la organización comprende que lo que se gana por medio de la imposición de un esquema restrictivo es mucho menos de lo que se pierde por la vía de la iniciativa, de la creatividad, de la lealtad, de la honestidad y de la solidaridad de la gente. Los valores éticos actúan como vectores de adhesión y motivación, más que como imperativos incondicionales o patrones legales.

Nuevamente recurro a Guédez para decir que el carácter ético de instituciones como la universidad favorece en ellas las relaciones internas y externas así como la sustentabilidad organizacional.

- La ética es la esencia mediadora entre el hombre con Dios, con la naturaleza y con los semejantes, desde la perspectiva de nosotros mismos. En la dimensión de los semejantes ubicamos también 
los vínculos con el grupo, con las instituciones y organizaciones, con el país y, en general, con el resto del mundo. Desde el mismo momento en el cual se debilitan o rompen esos vínculos se promueven los desequilibrios éticos.

- Así como se recurre a la sustentabilidad para destacar el sentido equilibrado y abarcador del desarrollo, de igual manera es posible pensar en un concepto de sustentabilidad empresarial. La clave del éxito gerencial está dada por la capacidad de combinar lo que se puede hacer (factor conocimiento), con lo que se quiere hacer (factor emocional) y con lo que se debe hacer (factor ético).

Pero más allá de estas diferencias, aflora la posibilidad de conjugar el poder, el querer y el deber en un círculo virtuoso en el cual se promueva un reforzamiento progresivo y acumulativo entre estas tres dimensiones. El poder da fuerza, el querer promueve rumbo y el deber aporta claridad.

Cooper (1998) sostiene que recientes investigaciones subrayan que las emociones sirven de energía a los valores éticos, tales como la confianza, integridad, empatía y credibilidad, así como también promueven una mejor relación con el entorno comunitario, que es también parte de la responsabilidad ética de las empresas.

Pienso con Guédez (2001) que "la ética, además de ser un asunto de principios y convicciones, es también una cuestión de inteligencia. Las personas y las organizaciones que no asumen una claridad de reglas y una transparencia de conductas están condenadas al fracaso".

La ética es un asunto de inteligencia empresarial, en tanto que está en la base de las decisiones justas, del liderazgo eficiente, de las comunicaciones transparentes, de las relaciones abiertas, de los logros sólidos y de las innovaciones clave.

Cabe igualmente señalar que así como Pascal (2008) sostenía que el corazón tiene razones que la razón no conoce, de manera semejante puede sostenerse que el espíritu ético tiene también razones que ni la razón ni el corazón conocen. A partir de la ética, las universidades tienen más autoridad y generan una mayor capacidad persuasiva. También a partir de la ética, las organizaciones aseguran incrementar la capacidad para saber y saber hacer, así como para hacer más y mejor con lo que se tiene y se sabe. Finalmente, a partir de la ética, las instituciones amplían la capacidad de relación y de interacción en todos los órdenes del entorno.

El equilibrio y coherencia de la cultura organizacional lo proporciona la ética, y ésta es una de las razones por las cuales la ética tiene que dejar de reflejar la atomización de conductas individuales para convertirse en la manera de pensar, sentir, decir y hacer de la organización como un todo.

Las instituciones, léase universidades, con o sin fines de lucro, dice Krygier (2001) constituyen una unidad social, no sólo para la producción en su línea específica, sino también para prestar servicios y satisfacer necesidades económicas, políticas, sociales y culturales a los que participan en ella y al entorno en que se desenvuelven y en el cual influyen. Como afirma Varela, la ética se debe acercar más a la sabiduría que a la razón; más a ser bueno que a un juicio correcto en una situación dada; a un compromiso activo desde una tradición que identifica lo bueno".

Para concluir este apartado no puedo dejar de subrayar también la importancia del liderazgo ético de la universidad en la sociedad. Y a nivel interno, uno de sus roles más importantes de las autoridades es ser maestros éticos para los diversos estamentos de la institución.

\section{El catedrático y la vida ética universitaria}

Si partimos, como lo venimos haciendo, de que la ética define el modo de ser humano, tanto del individuo como de la sociedad, es fácil comprender que existe una vinculación muy estrecha entre ética y profesión de profesor universitario.

Según sostiene Cordero (1986) esa vinculación es doble:

- Una vinculación esencial, que afecta al ser propio de la profesión educativa, en cuanto consiste en un quehacer humanizador y, por lo mismo, ético en su esencia. 


\section{UNIFÉ - EPG}

- Una vinculación operativa por cuanto el ejercicio de la profesión de educador va a constituir uno de los ámbitos de la actividad humana singularmente necesitados de la guía y regulación de una ética normativa.

Para precisarestas vinculaciones creo conveniente analizar someramente la vocación del docente, su desempeño profesional y su liderazgo ético.

\subsection{La vocación}

Entiendo la vocación como el llamado de Dios, a través de la sociedad, a desempeñar en ella la función para la cual cada quien se siente más capacitado. Para otros autores es la inclinación o propensión personal, y el ajuste entre la inclinación y las cualidades no sólo técnicas sino también humanas.

La profesión de profesor universitario asume un carácter globalizante, que no permite paréntesis efectivos, ni en la ocupación ni menos aún en la preocupación. Tampoco permite segmentación en parcelas de la vida, sino que el educador tiene que comunicarse en toda su personalidad, en sus conocimientos y en sus valoraciones, en su saber y en su amor, en su habilidad técnica y hasta en el dominio controlado de su temperamento, es decir, en su carácter virtuosamente formado. No le es posible reservar nada de sí, de manera que eso no tenga incidencia en su labor profesional.

Como respuesta a su vocación, lo primero que debe hacer el profesor universitario, plantea Cardona (1990), es conseguir que su propia tarea sea un acto ético: debe actuar éticamente, como persona que se dirige a personas, y dar a esa relación recíproca que se establece un sentido moralmente bueno: ha de ser un acto personal bueno, en sí y en sus consecuencias. Ha de ser un buen profesor, siendo un profesor bueno.

Y a partir de ahí se trata de que cada docente, cualquiera que sea la especialidad o rama del saber o de la ciencia que cultive, tenga «también» una suficiente formación humanísticabásica, quelepermita aél mismo integrarla al sector al que se dedica habitualmente. El estudio de las llamadas «humanidades» es un modo de acercarse a ello. Ese profesor, así formado, tendrá a su vez que fomentar en sus estudiantes su interés por lo integralmente bueno, evitando que se polaricen demasiado hacia conocimientos de tipo técnico, que les pueden capacitar para el ejercicio de una profesión o para obtener un buen rendimiento económico de su trabajo.

Y no habrá peligro de que se plantee algún conflicto entre la moralidad general a que tiene que atenerse el educador o docente, en cuanto hombre, y los deberes específicos que le imponga su profesión. Este tipo de conflictos, que a veces parecerían surgir en otras profesiones, como la de médico, psicoterapeuta o abogado, queda del todo descartado en el caso de la profesión de educador. En él el compromiso ético profesional no sería más que una peculiar y singularmente urgente concreción de su compromiso moral general, como persona humana, miembro participe de una sociedad en trance de constante y creciente humanización o -lo que es lo mismo- de creciente moralización.

\subsection{El desempeño profesional}

Se dice que el ser humano es un ser moral por definición en cuanto y en la medida en que es dueño de si y de su comportamiento, en cuanto de un modo real es 'creador' y responsable de sí mismo. Y estaremos ante un sujeto ético, una persona realmente humana, en cuanto se trate de un agente que actúa en fuerza de un carácter del que a sí mismo se ha dotado. El deber de hacerse a sí mismo se configura entonces como el deber moral radical. Pues bien: la labor del auténtico profesional de la educación en la universidad va a consistir precisamente en ser una ayuda para esa autorrealización propia, para ese forjado del carácter de cada uno de los educandos, no poniéndose en su lugar, sustituyéndole o anulándole de algún modo, sino estimulando la personal afirmación de cada uno conforme a la profundidad del pensamiento de Tomás de Aquino cuando sostenía que "el que enseña no causa la verdad, sino que suscita en el discente el conocimiento de la verdad". En dependencia de este cometido de la tarea educativa, vemos cómo surge uno de los principales deberes éticos del profesional 
educador, que podría formularse como el principio del respeto consecuente hacia el educando, cuya personalidad debe ser estimulada hacia la propia afirmación y nunca anulada o suplantada.

La condición de la profesión educadora es social con un alcance radical por cuanto a través del ejercicio de esa profesión, en muy importante medida, se va construyendo la sociedad y configurando su modo de ser, en particular su modo de ser ético o su modo de ser, por el contrario, amoral y refractario a los valores éticos. Y ahí radicará precisamente la singular dimensión ética de su actividad: en que genera una sociedad ética en su estructura, susceptible de la realización en ella de los valores y contenidos éticos; o por el contrario una sociedad amoral, opaca y resistente a la afloración en ella de los comportamientos y contenidos éticos.

$\mathrm{Y}$ es por esto también que el profesor universitario que participa en la formación de un profesional debe tener muy claro los objetivos centrales del proyecto académico y conocer los términos en que está planteado el currículo que siguen sus estudiantes, independientemente de la materia específica que él enseña y de si proviene de otra Facultad. Debe considerarse miembro de un equipo interdisciplinario y sus estudiantes deben verlo como tal. Este es uno de los tantos compromisos no escritos, que sirven de sustrato a toda la labor docente y que son el punto de partida de la capacidad institucional para enfrentar su tarea. (Pascual, 1992)

Es por esto también que el dominio de estrategias es condición ética y pedagógica para ser profesor universitario. Resulta imprescindible que el profesor sea capaz de facilitar los aprendizajes mediante estrategias adecuadas, lo cual no quiere decir que todo profesor deba ser un especialista en didáctica. Se le pide que haga uso de formas de enseñanza que compatibilicen la individualización, la autonomía y el trabajo colectivo.

El aprendizaje es un proceso mediante el cual los estudiantes universitarios influidos por sus profesores que les aportan los contenidos, modifican su estructura de conocimientos respecto a un tema concreto cambiando sus actitudes y normas de comportamiento. Es decir que, al aprender cosas nuevas, aquello que previamente conocían queda modificado: reestructuran los propios conocimientos para dar cabida a los nuevos. Se trata, dice Gin, de un proceso dinámico e interactivo que no es el resultado de una copia idéntica de los contenidos enseñados, sino que su interiorización supone una elaboración o construcción personal y única, cada vez más compleja.

En este contexto, la enseñanza se define como el ajuste de la ayuda a esta construcción conjunta y personalizada porque los procesos de enseñanza y aprendizaje no se pueden concebir por separado.

Es por ello que requerimos de un enfoque pedagógico que, como señalaba Power (1996), se base en un aprendizaje sin fronteras que asegure procesos constructivos, estrategias y herramientas para ayudar a los estudiantes a obtener acceso, manipular, aplicar y evaluar críticamente la información de que disponen a fin de convertirla en conocimiento.

\subsection{El liderazgo ético en ese desempeño.}

Como bien señala Cordero (1986), "para el fructífero ejercicio de la profesión de educador, resulta imprescindible la cualidad ética que suele expresarse como autoridad moral". En efecto, la única autoridad que da la fuerza para actuar sobre los estudiantes sin anular al mismo tiempo su personalidad, sólo es la autoridad moral, que se define como un ascendiente reconocido y aceptado por ellos que perciben unas cualidades y una actitud específicas en su profesor. Las cualidades de referencia son cualidades ciertamente de conocimiento y experiencia, de aptitud técnica si se quiere, pero sobre todo de índole ética, como será la claridad y firmeza en los valores asumidos, que se expresan en la firme adhesión al deber.

Pero también debemos recordar que las instituciones educativas como la universidad son instituciones morales, diseñadas para promover normas sociales y los directivos son los líderes o agentes morales que a menudo deben tomar decisiones que favorecen un valor moral sobre otro. Por esta razón, el proceder de los líderes "debe ser deliberadamente moral". Su deber moral se expresa no sólo en los 


\section{UNIFÉ - EPG}

dilemas éticos del día a día, sino en las políticas y estructuras que pueden tener implicaciones éticas.

Y el propósito de la formación universitaria no se circunscribe a formar profesionales y técnicos, porque ella no se agota en su orientación hacia el trabajo. Por encima de todo, educamos para vivir, convivir y sobrevivir, y estos alcances son justamente los que provocan una simbiosis entre la ética y la educación. Debemos repetir que, en sus expresiones más prístinas, la ética se simplifica en tres significados: autoestima, solidaridad y participación. Este es el trípode esencial de la ética porque ella se enraíza en la creencia que cada quien tiene de sí mismo, se revela a través del querer ayudar al otro y, finalmente, se concreta en la traducción de las intenciones en logros correctos. En este orden, se aprecia que la autoestima nos hace vivir, la solidaridad nos permite convivir, y la participación promueve nuestro sobrevivir.

Y al respecto, Simons (1998) dice que es necesario caer en la cuenta de que "la ética o la moral no consisten en cumplir normas que se imponen arbitrariamente al hombre y que más bien parecerían estorbar su vida y realización humana. Pero tampoco es consecuente una ética relativista, individualista o pragmática que la hace depender totalmente de las diferencias de culturas, personas o intereses. Menos aún tiene sentido una ética fácil (light) del todo vale si me parece bien o me conviene".

Lo que acabo de expresar no se obtiene fácilmente. Para lograrlo es preciso luchar por una ética de la vida que no se agote en la vida misma como supervivencia, sino que desencadene situaciones generadoras de una ética de la naturaleza, una ética del desarrollo, una ética de la política, una ética del beneficio, y sobre todo, una ética de la solidaridad, capaces en sí mismas de descorrer el velo de nuestras posibilidades en un mundo con tantas expectativas y tanta incertidumbre a la vez. (Capella, 1991)

Con Savater (1999), podemos decir que la tarea fundamental de la humanidad es producir más humanidad; y con Lipovetsky (1991), que no es la ética lo que gobierna la comunicación de la organización, es ésta la que promueve los alcances y prolonga las proyecciones de aquélla.
Las instituciones que se inspiran en la concepción católica de la vida cuentan con el apoyo de la Iglesia pues, como afirma el Consejo Pontificio de la Cultura (1994), la Universidad y, de modo más amplio, la cultura universitaria constituyen una realidad de importancia decisiva. "En su ámbito se juegan cuestiones vitales, profundas transformaciones culturales, de consecuencias desconcertantes, que suscitan nuevos desafíos. La Iglesia no puede dejar de considerarlos en su misión de anunciar el Evangelio."

El Consejo va más allá al afirmar que "la síntesis entre cultura y fe no es solo una exigencia de la cultura, sino también de la fe ... Una fe que no se hace cultura es una fe que no es plenamente acogida, enteramente pensada o fielmente vivida"

\section{Referencias}

Adam, F. (1970). Andragogía. Ciencia de la educación de adultos. Caracas. Venezuela: Grafarte.

Astudillo, E. (1995). Proyecto Educativo Institucional y Gestión Escolar en un contexto descentralizado. En: Pensamiento. Revista de la Facultad de Educación de la Pontificia Universidad Católica de Chile.

Bacigalupo, L. (2001) "Un aporte de la ética a la cultura moral del Perú: lineamientos para un programa de regeneración de los valores" . 38 CADE PERU: ¿En qué país queremos vivir? La apuesta por la educación y la cultura. Lima, Perú.

Berlanga, B. (1994). Dignídad, Identidad y autonomía. Fundamentos centrales de una ética en la educación rural. En Nueva América, 61.

Capella, J. (1991). Educación y politica, Lima, Perú.

Cardona, C. (1990). Etica del quehacer educativo. Madrid, España: RIALP.

Castells, M. (2001). La era de la información. Economía, sociedady cultura. 1 La sociedad red. Madrid.

Cisneros, L.J. ( 19 de julio de 2009). Universidad y Reflexión. La República.

Cooper, R. y Ayman, S. (1998). La inteligencia emocional aplicada al liderazgo y a las organizaciones. Bogotá. Colombia: Norma. 
Cordero, J. (1986). Etíca y profesión en el educador. Revista Española de Pedagogía. 44 (2), OctubreDiciembre.

DeLonghi, A.L. (2005) Propuestas para un proceso de formación continua de docentes innovadores en educación en ciencias. En: De Longhi, A.L.; Ferreyra, A.; Paz, A.; Bermudez, G.; Solís, M; Vaudagna, E. y Cortez, M. Estrategias de enseñanza de Ciencias Naturales en el nivel medio. Córdoba, Argentina: Universitas.

Díez Hochleitner, R. (1996 ). Aprender para el futuro mejor: Educación y desarrollo. Documentos de un debate. X Semana Monográfica. Fundación Santillana. Madrid, España.

Giroux, H. Pedagogía crítica como proyecto de profecía ejemplar: cultura y política en el nuevo milenio, en: Imbernon, F.(coord.). La educación en el siglo XXI. Los retos del futuro inmediato. Barcelona, España: Graó.

Guédez, V. (2001). Proyecto Histórico Educativo. Caracas, Venezuela: Kapelusz.

Guédez, V. (2001). La ética gerencial. Instrumentos estratégicos que facilitan decisiones correctas. Caracas,Venezuela: Planeta.

Krygier, M. (2001). Transitional Questions about the Rule of Law: Why, What and How? East Central Europe. Eine wissenschatlicle Zeitschrift 28, (1).

Lipovetsky, G. (1991). El imperio de lo efimero. Barcelona, España: Anagrama.

López, E. (2011). ¿ ¿Sigue viva la ética cristiana? Diálogos de medianoche. Fe, filosofia y espiritualidad. México D.F, México.

Malraux, A. (1999). La condición bumana. Buenos Aires, Argentina: Edhasa

Mayor Zaragoza, F. (1987). "¿Universidad todavía?” En Educación, 4(4), Año IV, Julio-Octubre.

Mejia, M.R. (1996). Competencias y habilidades para una escuela del siglo XXI. Tarea. Revista de Educación y Cultura. Setiembre. Lima.

Morin, E. (1994). Introducción al pensamiento complejo. Barcelona,España: Gedisa.

Morles, A. (1998) Las demandas de la sociedad del futuro. En: Educación Hoy (Megababilidades en el siglo XXI), 133. Enero-Marzo.
Pascal, B. (2008). Pensamientos. Madrid, España: Cátedra.

Pascual, J. (1992). Innovación docente universitaria: un Proceso Institucional. Ponencia presentada en el Seminario Técnico Internacional "Innovación en educación universitaria en América Latina", organizado por CINDA, en Santiago de Chile, con el auspicio de OEA, PNUD y el Consejo Superior de Educación de Chile.

Regal, B. (1988) Fundamentos de Etica Profesional. Lima. Perú: Universidad de Lima.

Richardson, M. and others (1992) "Teacher Perception of Principal BehaviorA Study." Paper presented at the annual meeting of the Mid-South Educational Research Association, Knoxville, Tennessee, November 1992.

Salvat, P. (1994). Algunas paradojas de nuestra modernidad. En Nueva América, 61.

Sartre, J.P. (1943). El ser y la nada. Biblioteca de Obras Maestras del Pensamiento. México D.F., Mexico: Lozada.

Savater, F. (1982). Invitación a la ética, ensayo. Barcelona, España: Anagrama.

Secadas, F. (1995) Inteligencia y cognición. Revista de psicología general y aplicada. Madrid, España.

Sichel, B. (1993). "Ethics Committees and Teacher Ethics." In Ethics for Professionals in Education: Perspectives for Preparation and Practice, edited by Kenneth Strike and P. Lance Ternasky. New York: Teachers College Press.

Simons, A.Crisis y replanteamiento actual de la ética. En: Una ética para tiempos difficiles. Lima. Centro de Espiritualidad Ignaciana.

UNESCO (1998). Declaración Mundial sobre la Educación Superior en el Siglo XXI: Visión y Acción. Marco de Acción Prioritaria para el Cambio y el Desarrollo de la Educación Superior aprobados por la Conferencia Mundial sobre la Educación Superior. París, Francia.

Santa Sede (1994). Resencia de la Iglesia en la universidad y en la cultura universitaria. Consejo Pontificio de la Cultura. Ciudad del Vaticano, 22 de mayo. Solemnidad de Pentecostés. 